\title{
AN EXPERIMENTAL EVALUATION OF TRANSIENT FLOWS IN A SUPERSONIC GUN TUNNEL
}

\author{
Al Al-Falahi Amir, M. Z. Yusoff, and Diyar I. Ahmed \\ College of Engineering, Universiti Tenaga Nasional UNITEN \\ Jalan Kajang-Puchong, 43009 Kajang, Selangor, Malaysia. \\ Email: diyar@uniten.edu.my
}

\begin{abstract}
An experimental study has been performed to investigate transient flows in a supersonic gun tunnel. The experimental work was performed using a short duration high speed flow test facility at the Universiti Tenaga Nasional (UNITEN). A physical description of the facility along with the principles of operation is provided. The pressure history of the flow process was captured using a fast response pressure transducer at three stations located at the end of the facility. Experimental measurements of shock strength, peak pressure and shock wave speed change of Air-Air as a driver/driven gas are then presented and compared with a further set of experimental measurements using the gas combination of Helium-Air. The shock wave speed was measured experimentally with a two pressure transducers technique. The results showed that the existence of the piston has a very significant influence on both the moving shock wave and peak pressure value achieved. The results provide a very good estimate for the above-mentioned parameters obtained after diaphragm rupture, and also provide a better understanding of the parameters that affect the performance of the facility.
\end{abstract}

Keywords: Gun tunnel; shock strength; peak pressure; shock wave speed.

\section{INRODUCTION}

Research in supersonics is conducted using ground-based experimental facilities, computational fluid dynamics (CFD) and actual flight tests using rocket powered flight vehicles. CFD is the least expensive; however it requires extensive code verification and may encounter problems in correctly modeling complex flows. Flight test programs offer very useful information, but can be relatively expensive and require a large amount of initial development work. Ground-based experimentation offers verification for the CFD portion of the development and also the preliminary design information for flight test programs. Ground-based experimental work is therefore an important research component for hypersonic vehicle development programs. Information made available through experimental programs ranges from the quantitative measurements of parameters, such as heat transfer, forces, momentums and pressures, to the visualization of shock/shock-shock/boundary layer interactions, as well as illustrations of the effects of the control surfaces.

The main objective of the experimental supersonic program at UNITEN is to obtain data in a supersonic environment on partial body configurations. The experiments aid in identifying local flow phenomenon, and can be applied to larger more extensive studies. This paper discusses several investigations on shock waves that were performed experimentally within the operating conditions of a supersonic gun tunnel at the UNITEN, in order to extend its operating Reynolds and Mach number 
range. From a practical point of view, the facility is much more useful and offers a broader simulation range. The facility components, principles of operation and physical description are described in the following sections.

\section{OVERVIEW OF THE FACILITY}

UNITEN's test facility has been designed, built, and commissioned for different values of diaphragm pressure ratios in order to obtain a wide range of Mach numbers. The facility consists of two sections, a driver and driven section separated by a thin aluminum diaphragm. The driver and driven section have a cylindrical shape of $50 \mathrm{~mm}$ inner diameter and $90 \mathrm{~mm}$ outer diameter. The details of the components of the facility are described briefly in the following section and shown in Figure 1 [for further details and operating procedure see Al-Falahi (2008)].

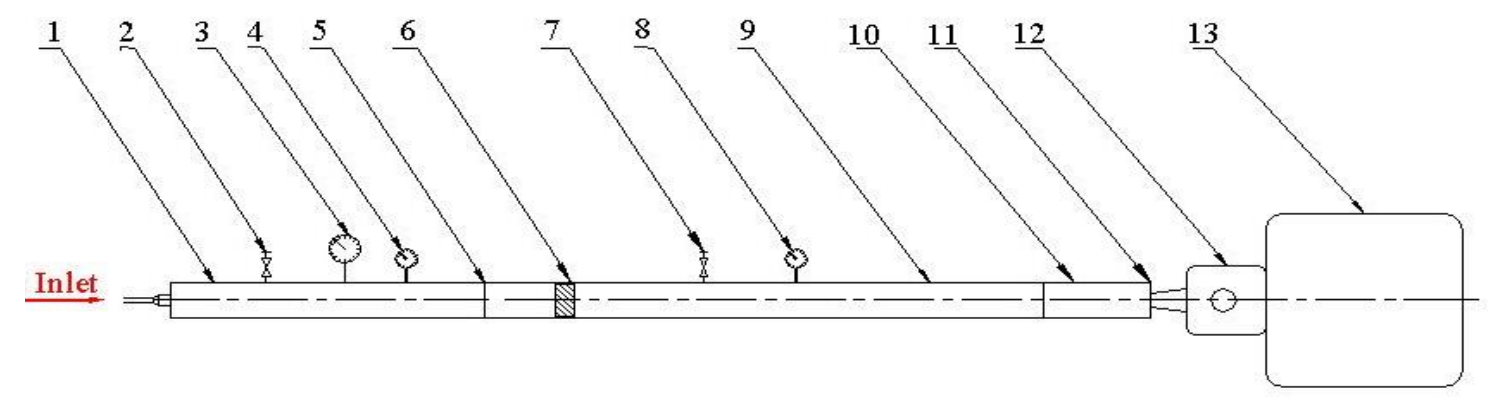

Figure 1. Schematic of UNITEN's facility

1. Driver section: - A high-pressure section (driver) which contains the high pressure driver gas, the driver gas can either be air, helium, hydrogen or other light gases.

2. Discharge valve: - To discharge the driver section after each run.

3. Pressure gauge: - To read the pressure inside the driver section, this section is also provided with a static pressure transducer to record the exact value of the driver pressure $\mathrm{P}_{4}$ at which the diaphragm ruptures.

4. Vacuum pump: - When the driver gas is not air (e.g. helium or hydrogen) then the driver section should be evacuated and refilled with the required driver gas.

5. The primary diaphragm: - This is a thin aluminum membrane to isolate the lowpressure test gas from the high-pressure driver gas until the compression process is initiated.

6. Piston compression section: - A piston is placed (in the driven tube) adjacent to the primary diaphragm, so that when the diaphragm ruptures the piston is propelled through the driven tube, compressing the gas ahead of it. This piston is used in the gun tunnel set up.

7. Discharge valve: - To discharge the driven section after each run.

8. Vacuum gauge: - To set the pressure inside the driven section to achieve values (vacuum values) lower than the atmospheric value.

9. Driven section: - A shock tube section (smooth bore), to be filled with the required test gas (air, nitrogen or carbon dioxide).

10. Driven section extension: - The last half meter of the driven section on which the pressure transducers and thermocouples are attached. 
11. The secondary diaphragm and nozzle section: - A light plastic diaphragm to separate the low pressure test gas inside the driven section from the test section and dump tank, which are initially in a vacuum state prior to the run. The main purpose of the second bursting system is to rapidly relieve pressurized air and expand through a convergent-divergent nozzle once the desired pressure has been reached. The convergent-divergent nozzle converts subsonic flow to supersonic flow.

12. Test section: - This section will expand the high temperature test gas through a nozzle to the correct high enthalpy conditions needed to simulate hypersonic flow. A range of Mach numbers is available by changing the diameter of the nozzle throat insert.

13. Vacuum vessel (dump tank): - To be evacuated to about $0.1 \mathrm{mmHg}$ pressure before running. Prior to a run, the driven section, test section and dump tank are to be evacuated to a low-pressure value.

Three significant items can be classified in UNITEN's facility as follows:

- Shock tube

- Convergent-divergent nozzle

- Instrumentation/data acquisition system

The specifications of the shock tube are provided in Table 1. The operational procedure of the shock tunnel system can be achieved with only one person. Before operating the shock tunnel it is very important to make sure that there is no pressure in either the driver or driven section. This can be achieved by opening discharge valve 1 and discharge valve 2, located on the barrel and the driver section [see Figure 1]. There are two sheets of thin diaphragm along the facility, they need to be installed and the driver section refilled with the desired pressure ratio until the primary diaphragm ruptures. During this the data acquisition must be on to record the pressure at the four stations. Data acquisition stops at the end of the process.

A conical convergent-divergent nozzle is attached to the end of the low pressure section (driven section). This section will expand the high temperature test gas traverse a nozzle to the correct high enthalpy conditions needed to simulate high speed flow. It has a throat of $7 \mathrm{~mm}$ in diameter, exit diameter of $70 \mathrm{~mm}$ and total length of $389 \mathrm{~mm}$. To separate the driven tube and test section, a very thin sheet is used as a small diaphragm at the end wall of the shock tube. Figure 2 shows UNITEN's high speed flow test facility.

Table 1. UNITEN's shock tube specifications

\begin{tabular}{ll}
\hline \multicolumn{1}{c}{ Parameters } & Value \\
\hline Driver section length & $8.3 \mathrm{ft}$ \\
Driven section length & $13.24 \mathrm{ft}$ \\
Max. driver pressure & $1015 \mathrm{psig}$ \\
Driver temperature & Room T \\
Tube inner diameter & $1.9685 \mathrm{in}$ \\
Driven test gas & Air, $\mathrm{CO}_{2}$ \\
Main diaphragm ultimate bursting pressure & $174 \mathrm{psi}$ \\
\hline
\end{tabular}



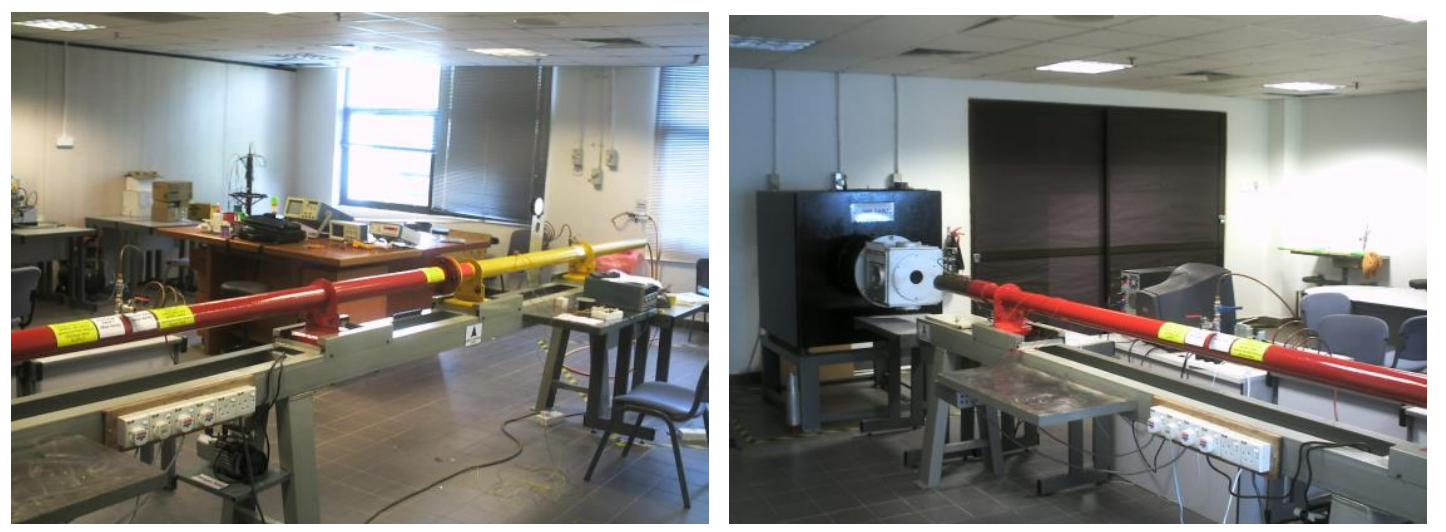

Figure 2. UNITEN's high speed flow test facility

\section{PRINCIPLES OF OPERATION}

The shock tube has limitations in terms of flow Mach number capabilities (Lukasiewicz, 1973). Hertzberg et al. (1962) originally suggested a modification to the conventional shock tube in order to generate hypersonic Mach numbers. A convergent-diverging nozzle added to the end of the low pressure section (driven section) of a conventional shock tube permits the establishment of steady flow Mach numbers, far exceeding those that can be achieved using a conventional shock tube. This modification to the basic shock tube, which is by far the most economic hypersonic research facility, is referred to as the "Shock Tunnel". A high-enthalpy shock tunnel is one of the most used hypersonic flow simulation facilities. It produces a high speed flow by using a converging-diverging nozzle, where the reservoir gas can be created by shock wave reflection at the end of the shock tube (Boyce and Stumvoll, 2007). The shock tunnel typically includes a shock tube, which is a convergent-divergent nozzle at the downstream end of the driven section (low pressure section) of the shock tube (Olivier et al, 2002). This nozzle expands the supersonic flow behind the reflected shock wave to hypersonic speeds (Chue and Eitelberg, 1998), so that a higher Mach number flow with full stagnation temperature simulation can be obtained, and a diaphragm between the nozzle and the driven section. The driver is initially filled with high pressure gas, with a high speed of sound (typically air, helium, nitrogen or argon), which may be heated to further increase its sound speed and enthalpy (Stalker et al., 2005). The driven tube is initially filled with the test gas, usually air, $\mathrm{CO}_{2}$ or nitrogen, at a much lower pressure.

When a predetermined pressure rise is achieved, the primary diaphragm (or burst disk) between the drive and the driven section in the shock tube is ruptured and the high pressure driver gas rushes into the driven section, introducing a shock wave which compresses and heats the driven gas (Mundt et al., 2007). The flow in a real facility is initiated by the rupture of an aluminum diaphragm. After diaphragm rupture, a strong shock wave is driven through the test gas in the shock tube (low pressure section), followed by the driver gas/driven gas interface - the so-called contact surface (discontinuity surface). When the generated shock reaches the end of the driven tube, the second diaphragm at the nozzle entrance is ruptured and the processed test gas expands through the nozzle into the test section (Craddock, 1999). The shock is reflected from the end of the driven tube, and a constant property region with the heated and compressed gas behind the reflected shock is generated for a very short time, thus creating the high enthalpy nozzle supply gas. (It should be noted that the high enthalpy obtained in a reflected shock tunnel comes via compression by two shocks - the 
reflected shock interacts with the contact surface and is then partly reflected back toward the nozzle.) The gun tunnel shown in Figure 3 (Al-Falahi et al., 2004) is quite similar in operation to the shock tunnel. It includes a high-pressure driver section and a low pressure driven section, with a diaphragm separating the two. Gun tunnel facilities use a free piston compression process to produce a high pressure gas reservoir at a moderate temperature. This gas reservoir can then be expanded with an appropriate nozzle contour to produce a short duration test flow for gas dynamic and aerodynamic experiments (Mallinson et al., 2000).
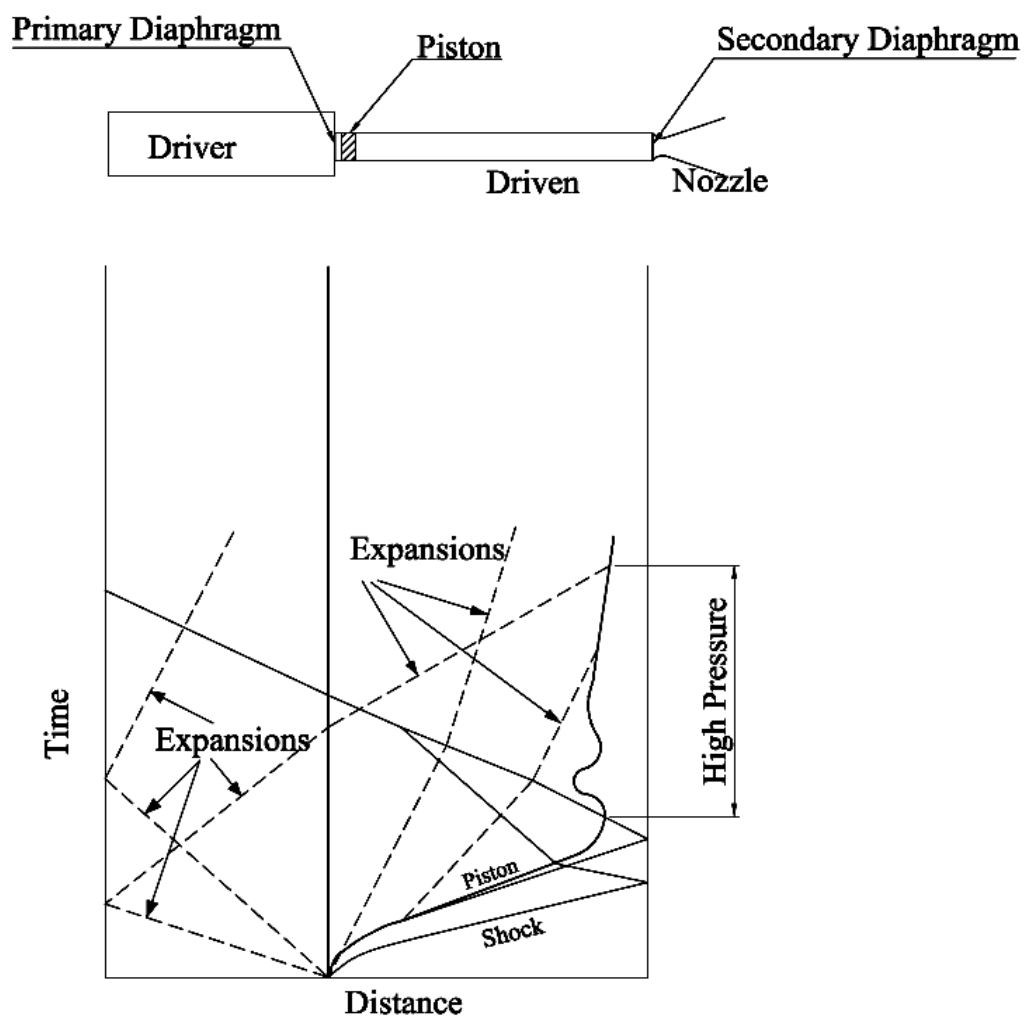

Figure 3. Gun tunnel and wave diagram

A gun tunnel works in exactly the same manner as a shock tunnel, except that instead of using a shock wave to compress the initially low pressure driven gas, a lightweight piston is used. A piston is placed in the driven tube adjacent to the diaphragm. The piston used is constructed of lightweight and high strength plastic so that it can be accelerated to velocities considerably above the speed of sound in the driven gas (Al-Falahi et al., 2004). When the diaphragm is ruptured, the driver gas pushes a piston down the low pressure section. The piston is travelling at a supersonic velocity and therefore a shock wave is also created in front of the piston causing further heating and forces on the piston (Edney, 1967). The main purpose of the light piston is to compress the gas in front of it, heat it, and then move towards the end of the shock tube. The piston comes to rest with equal pressure on its two sides, and the heated and compressed driven gas ruptures a diaphragm and flows through the nozzle. As the piston travels through the driven section it overshoots its equilibrium position, causing a pressure peak (Stalker, 1965). This transient rapidly disappears, and the pressure of the driven gas essentially remains constant until the gas is exhausted or until an expansion 
wave from the driver section reaches the piston. The flow ends in the dump tank, at which the process is complete.

\section{DATA ACQUISITION SYSTEM}

Data is collected digitally through a data acquisition system. A Graphtec DAQ (model Midi Logger Dual GL500), with 24 channel, and a digital recorder with a maximum sampling rate up to $500 \mathrm{M}$ sampling/sec per channel was used to gather the pressure information. Channels 1 and 2 were used to gather data from the PCB pressure transducers, which have been used as shock tube instrumentation to analyze the transient time of the incident and reflected shock waves. Channel 3 was used to reveal the history of the pressure along convergent-divergent nozzle section, while Channel 4 monitored the diaphragm burst pressure, to provide a precise value for the pressure ratio $\left(P_{4} / P_{1}\right)$. A schematic diagram of the instrumentation and data acquisition system is shown in Figure 4.

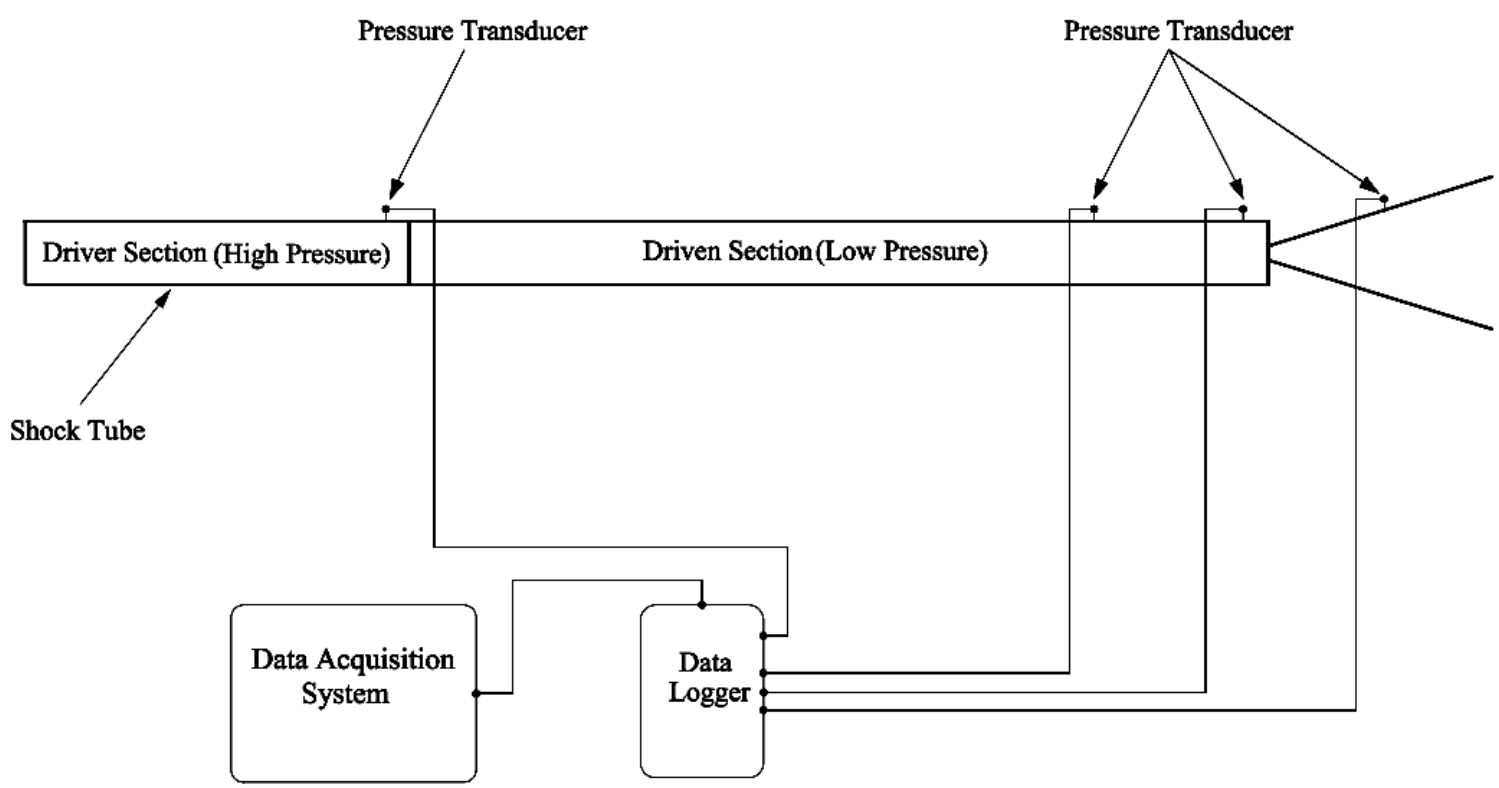

Figure 4. Data acquisition system

The electrical signals received from the sensors are very small (in mv), so they pass through the data logger before they proceed to data acquisition and finally to the computer, which is provided with appropriate software to draw the pressure history at the three stations along the whole facility. Graphtec is used to capture the data (pressure distributions at stations 1, 2, 3 and 4) from the data logger before being transferred to the computer. The pressure history will be displayed and automatically drawn by the software as shown in Figure 5.

A specified range of data in the pressure history will be selected using the "Display Cursor". The required ( $\max$ and min values) range of time (x-axis) and pressure (y-axis) are chosen before being transferred to Excel. Therefore, the data displayed in Excel are within the range chosen by the user based on the desired processing time along the facility. To investigate the effect of the piston on the facility, a set of experiments have been conducted with the gun tunnel test facility (with piston). 
The pressure histories at the nozzle-reservoir (end of the extension section) and along the nozzle section are measured with a pressure transducer (PCB Piezotronics Inc., model 482A21), the two sensors capturing the nozzle reservoir pressure were located at the end of the driven section, the first is instrumented at $x=3653 \mathrm{~mm}$ from the primary diaphragm section, the second station is located $342 \mathrm{~mm}$ from the first station. On the subject of the nozzle profile, however, a third station was positioned $195 \mathrm{~mm}$ downstream of the nozzle, as shown in Figure 6. The average shock speed along the shock tube is determined from the transit time between the primary timing station (station 1) (PCB Piezotronics Inc., model 482A21) and the nozzle-reservoir pressure transducer (station 2). The distance between the two stations is $342 \mathrm{~mm}$.

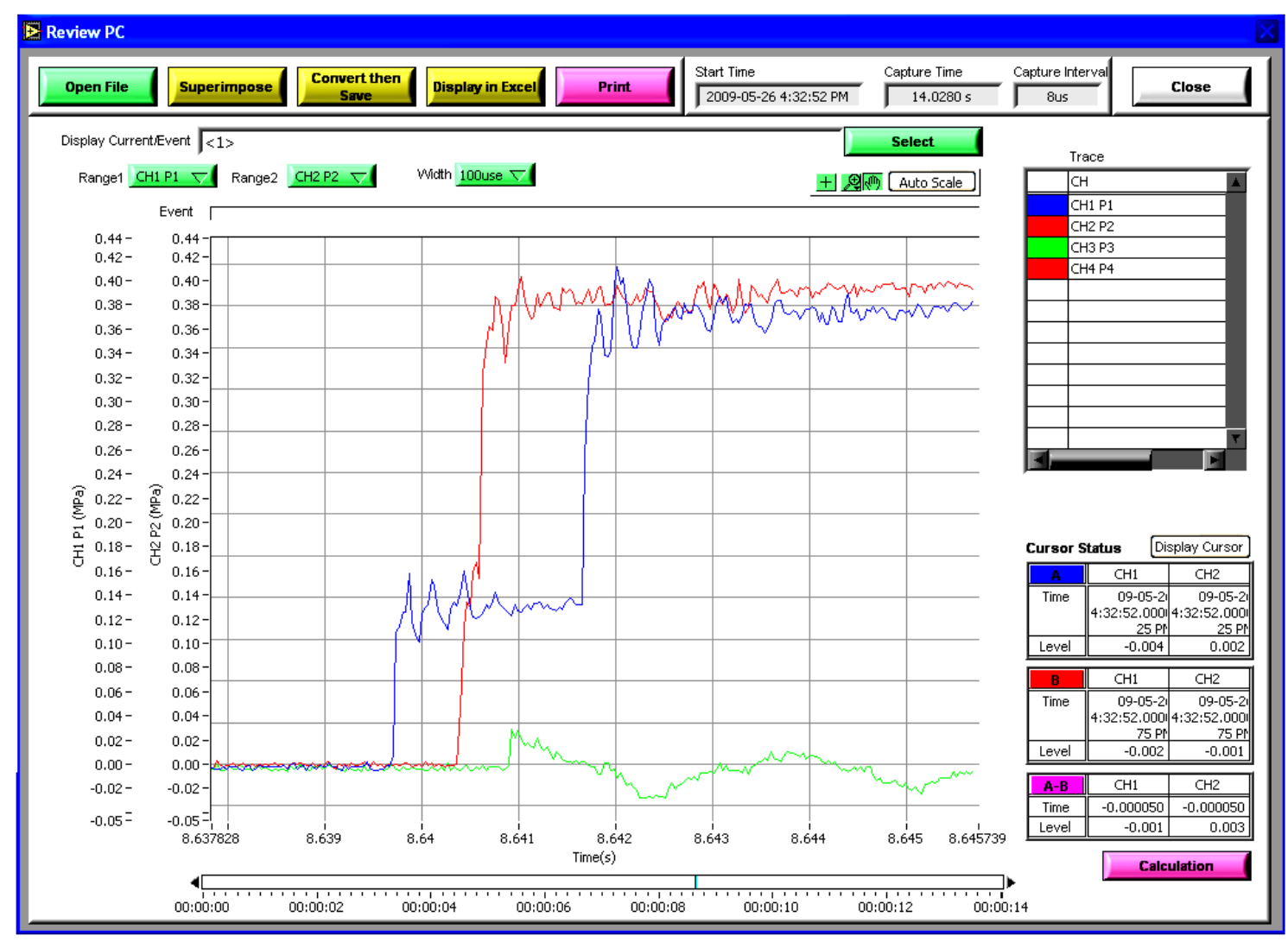

Figure 5. Sample of pressure history using air-air at three stations in the driven end and along the nozzle section using Graphtec software.

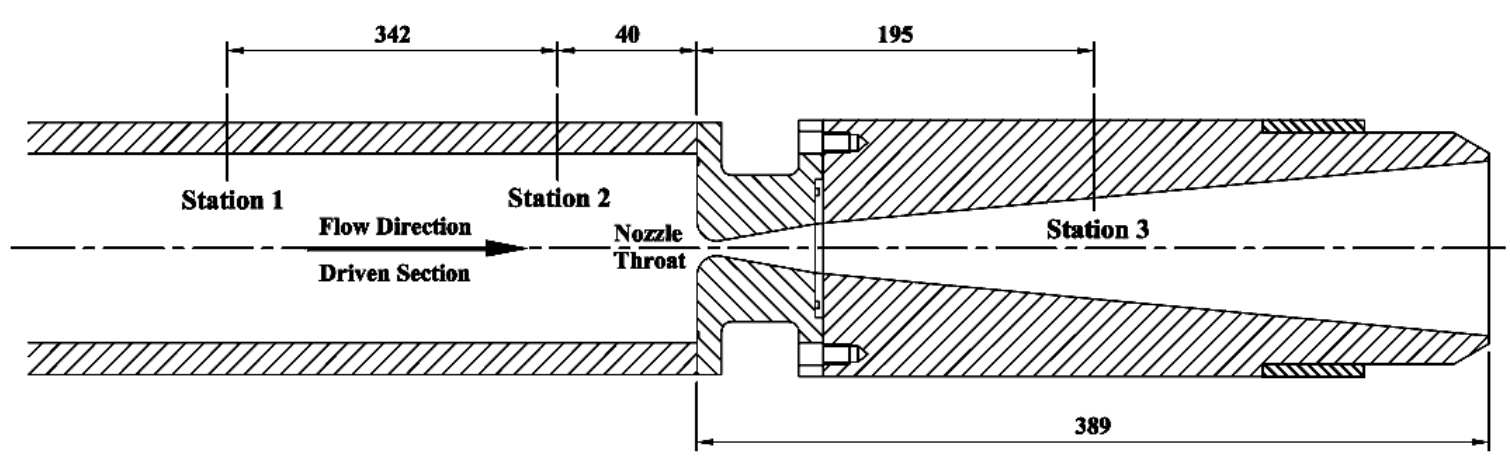

Figure 6. Schematic of three data stations 


\section{RESULTS AND DISCUSSION}

To provide a clear image of the piston along the driven section and the incident shock wave reflections ahead of the piston and the end driven section, an experiment has been performed for an Air-Air gas combination at a pressure ratio $P_{4} / P_{1}$ of 18 , as shown in Figure 7. This figure shows the pressure history at station (1), as can be seen the shock wave is marked (1) as it moves from the piston to the end driven section. After the shock wave hits the end wall some of it will eject downstream of the nozzle section and some will be reflected back towards the piston, due to the reflection of the shock wave the pressure will increase and as a result the shock wave causes a further increase in pressure, this can be noted in point (2). Furthermore, due to the compression of the piston the pressure increases gradually between points (1) and (2). There is another reflection of the shock wave from the piston which moves towards the end wall of the driven section, this will cause a third pressure jump as a result of the wave compression, as noted in (3).

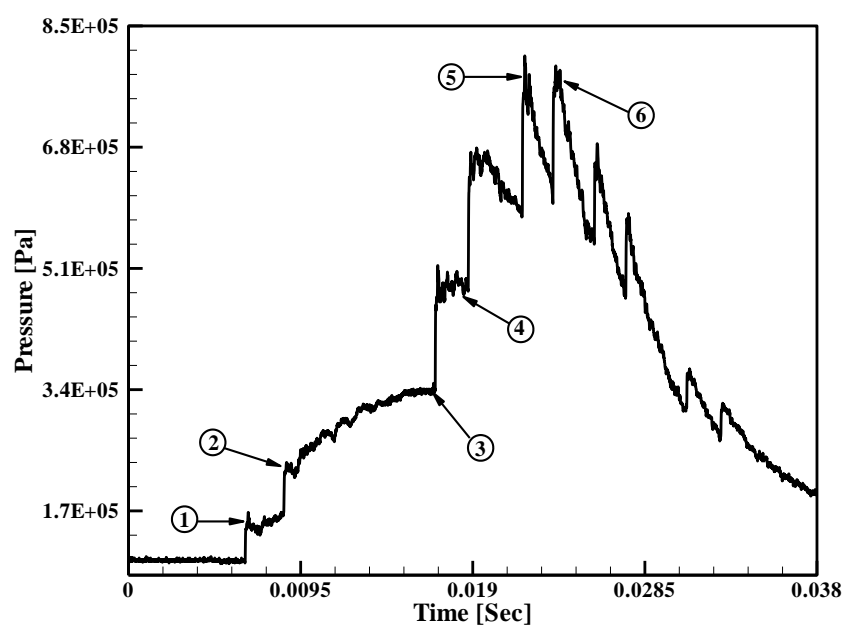

(1)

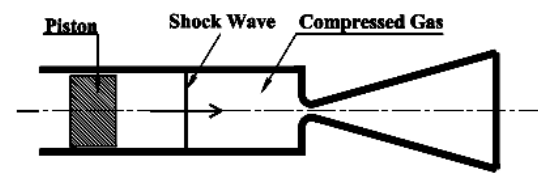

(2)

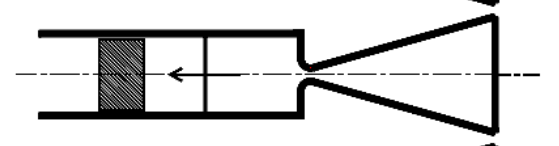

(3)

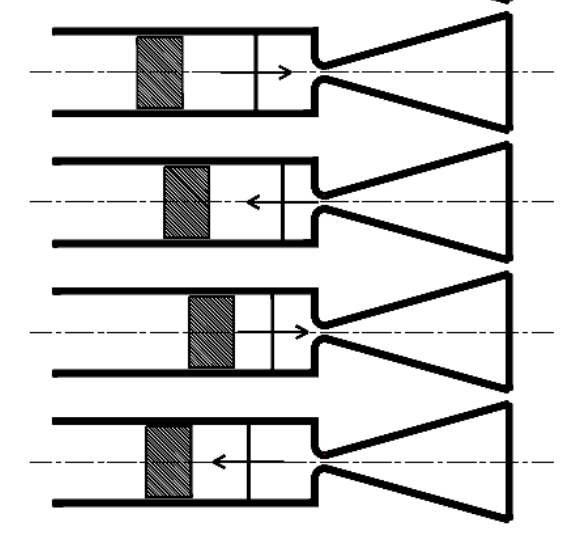

(6)

\section{(4)}

(5)

Figure 7. Experimental pressure history and piston's trajectory inside driven section 
As a result of the wave reflection from the piston, it will then reflect from the end wall and proceed back to the left, causing a further increase in pressure, as shown in point (4). So far, the piston still proceeds downstream of the driven section, the reflected wave will then hit the piston and is reflected in the opposite direction, which compresses the gas further causing the pressure jump to reach the peak pressure value of the whole process, denoted (5). After the piston has overshot its equilibrium position, it will be pushed upstream (left direction) by the compressed gas and then come to rest, although a pressure rise is still noticed due to the continuity of the shock reflection process, as marked by point (6). Finally, the pressure decreases rapidly since equilibrium of the pressure along the facility has been achieved.

\section{Shock Strength and Peak Pressure}

To investigate the effect of the piston on the facility, two sets have been performed for two gas combinations, Air-Air and He-Air as driver/driven gas for a selected diaphragm pressure ratio of 20. Figure 8 shows the pressure plot at the second station for Air-Air and He-Air gas combinations of shots in the gun tunnel facility. As can be seen, the shock strength is decreased when Air-Air combination is used. However, the pressure peak of the He-Air combination is higher. The He-Air shot shows a remarkable improvement in terms of both shock strength and pressure peak. It is significant to mention here that the He-Air combination can produce a pressure peak of about 62 bar, compared to the 40 bar of Air-Air, which denotes a percentage increase of more than $25 \%$.

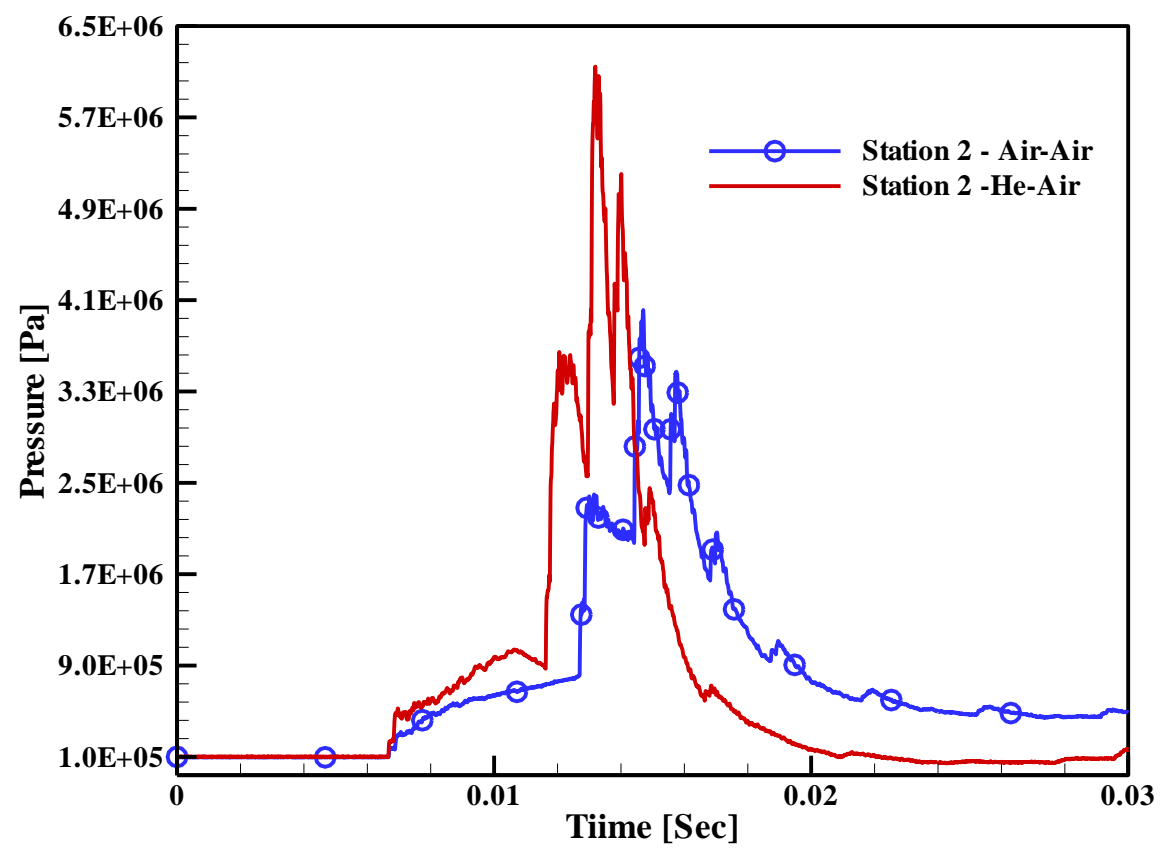

Figure 8. Experimental pressure history at station 2

\section{Shock Wave Speed}

The shock wave speed is measured experimentally using the two pressure transducer technique. The distance between the two piezoelectric pressure transducers at station 1 and station 2 is $0.342 \mathrm{~m}$, and the time the shock wave travels from station 1 to station 2 
can be obtained from the pressure history graph, as shown in Figure 9. The shock wave speed and Mach number can then be calculated. Figure 9 shows the experimental pressure history with the Air-Air gas combination at a selected pressure ratio $P_{4} / P_{1}=$ 20. The shock wave speed and Mach number are $450 \mathrm{~m} / \mathrm{s}$ and 1.3 , respectively. Similarly, Figure 10 shows the pressure history at stations 1 and 2 for the He-Air shot at a pressure ratio of 20 . The shock speed and shock Mach number are $684 \mathrm{~m} / \mathrm{s}$ and 2, respectively. It is worth mentioning that the shock speed with the He-Air shot is about $34 \%$ higher than the Air-Air shot. It can be concluded that the shock strength, shock speed and peak pressure improve when He is used as the driver gas instead of Air, since Helium gas is very efficient in producing strong shocks because it has a high speed of sound as a result of its very low molecular weight (Anderson, 2003).

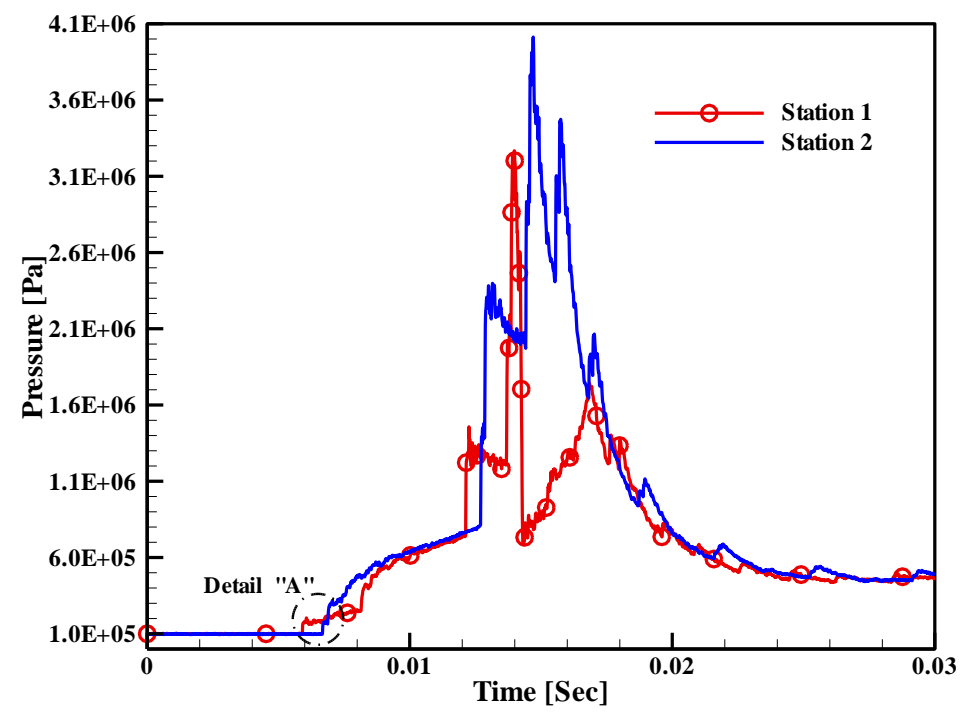

(a) Pressure history

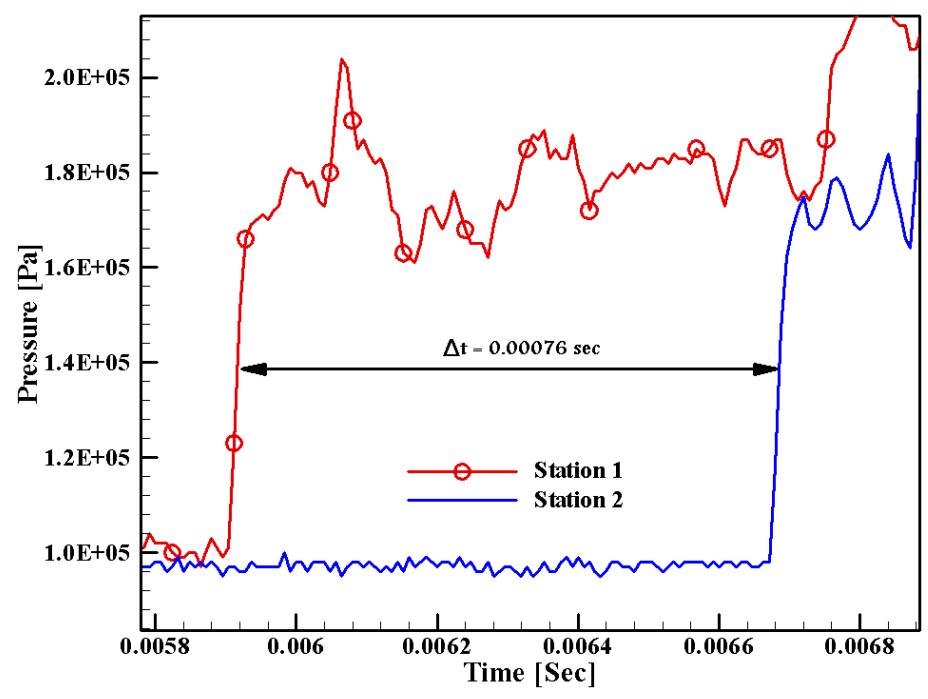

(b) Detail "A"

Figure 9. Pressure history at stations 1 and 2 (Air-Air; $\left.P_{4} / P_{1}=20\right)$ 


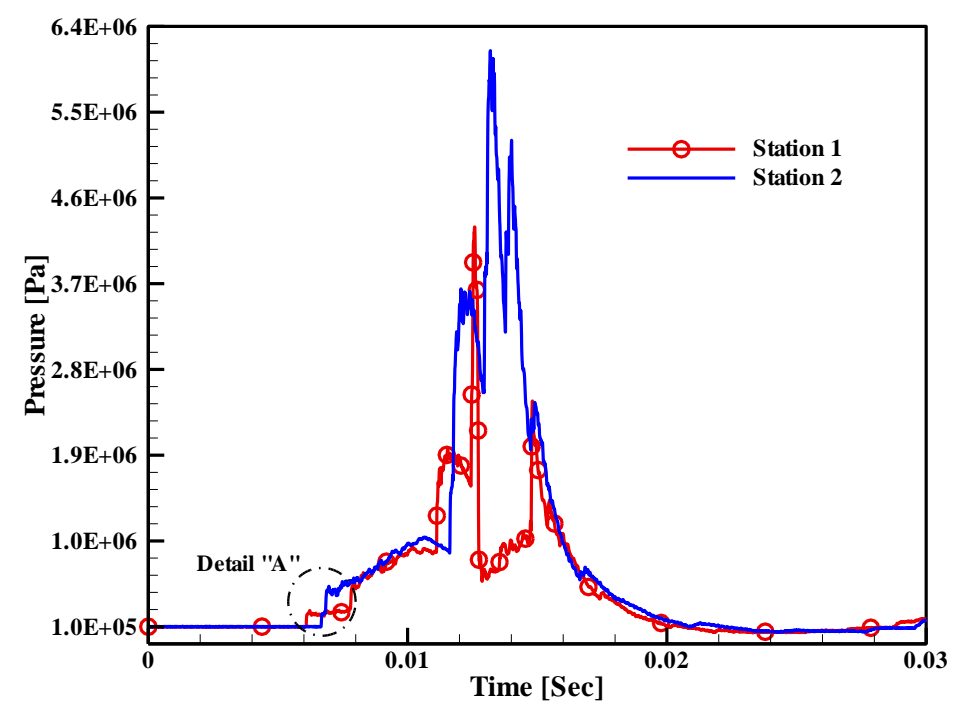

(a) Pressure history

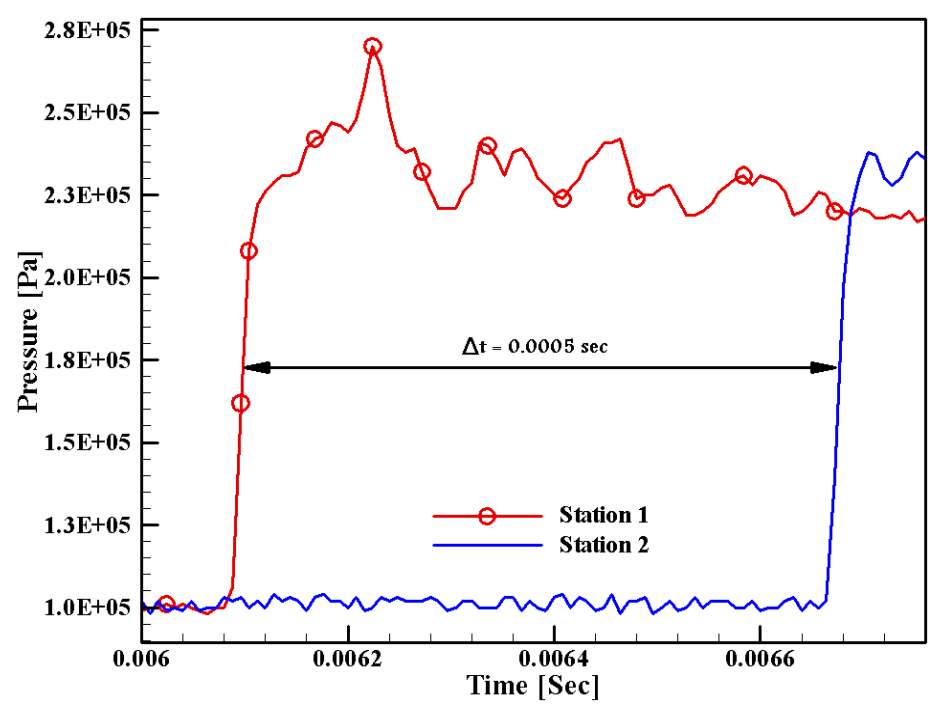

(b) Detail "A"

Figure 10. Pressure history at stations 1 and $2\left(\mathrm{He}\right.$-Air; $\left.P_{4} / P_{1}=20\right)$

\section{CONCLUSIONS}

The results show that for Air-Air driver/driven gases, the shock strength is decreased when the piston is used. However, the peak pressure of the He-Air shot is higher than that of the Air-Air shot. In spite of this, the He-Air shot shows a tremendous improvement in terms of both shock strength and shock speed. The shock wave speed now can be measured experimentally using a two pressure transducer technique. Shock speed can be increased by raising the diaphragm pressure ratio, or more powerfully by raising the speed of sound in the driver gas. To achieve high Mach numbers it is essential to raise the ratio of the speed of sound $\left(a_{4} / a_{1}\right)$ if excessive pressures are to be avoided. 


\section{ACKNOWLEDGEMENT}

Financial support provided by the Universiti Tenaga Nasional (UNITEN) is gratefully acknowledged.

\section{REFERENCES}

Al-Falahi, A. 2008. Design construction and performance evaluation of short duration high speed flow test facility. PhD Thesis, University Tenaga Nasional, Malaysia.

Al-Falahi A., Yusaf, T. and Zamri, M. 2004. Hypersonic free piston compression wind tunnel design and construction. Proceedings of the Conference on Advances in Malaysian Energy Research, Bangi, Selangor, Malaysia.

Anderson, J.D. 2003. Modern compressible flow. 3rd ed. New York: McGraw-Hill.

Boyce, R.R. and Stumvoll, A.K. 2007. Re-entry body drag: shock tunnel experiments and computational fluid dynamics calculations compared. Shock Wave, 16, 431443.

Chue, R.S.M. and Eitelberg, G. 1998. Studies of the transient flows in high enthalpy shock tunnels. Experiments in Fluids, 25: 474-486.

Craddock, C.S. 1999. Computational optimization of scramjets and shock tunnel nozzles. PhD Thesis, University of Queensland Brisbane, Australia.

Edney, B.E. 1967. Temperature measurements in a hypersonic gun tunnel using heat transfer methods. Journal of Fluid Mechanics, 27 (3), 503-512.

Hertzberg, A., Wittliff, C.E. and Hall, J.G. 1962. Development of shock tunnel and its application to hypersonic flight. Progress in Astronautics and Rocketry, 7, 701.

Lukasiewicz, J. 1973. Experimental methods of hypersonics. Gas Dynamics Series, Vol. 3. New York:Marcel Dekker Inc.

Mallinson, S.G., Hillier, R., Jackson, A.P., Kirk, D.C., Soltani, S. and Zanchetta, M. 2000. Gun tunnel flow calibration: defining input conditions for hypersonic flow computations. Shock Waves, 10: 313-323.

Mundt, C., Boyce, R., Jacobs, P. and Hannemann, K. 2007. Validation study of numerical simulation by comparison to measurements in piston-driven shock tunnels. Aerospace Science and Technology, 11: 100-109.

Olivier, H., Jiang, Z., Yu, H. and Lu, F.K. 2002. Detonation-driven shock tubes and tunnels. In: Lu, F. K. \& Marren, D. E. (eds.) Advanced hypersonic test facilities. Reston, VA, AIAA, pp. 135-203.

Stalker, R.J. 1965. An approximate theory of gun tunnel behaviour. Journal of Fluid Mechanics, 22(4): 657- 670.

Stalker, R.J., Paull, A., Mee, D.J., Morgan, R.G. and Jacob, P.A. 2005. Scramjets and shock tunnels - the Queensland experience. Progress in Aerospace Science, 41: 471-513. 